\title{
An embodied approach to testing musical empathy in subjects with an autism spectrum disorder
}

Leen De Bruyn ${ }^{1}$, Dirk Moelants ${ }^{1}$, Marc Leman $^{1}$

${ }^{1}$ Ghent University, Department of Musicology (IPEM)

\begin{abstract}
We present an empirical and qualitative study testing musical empathic ability in subjects with an autism spectrum disorder (ASD). Four experiments requiring an increasing level of empathy with music, from synchronization and attuning to emotional empathy, were carried out, using kinematic devices for measuring embodied listening responses and a verbal emotion attribution task. Results suggest that people with ASD have a corporeal understanding of the affective features of music, since they are able to mirror structural and even affective features of the music into corporeal articulations. However, this corporeal understanding does not give them a straightforward access to the emotional content of the music. The subjects with ASD seemed to rely on disembodied cognitive processes to attribute affects to music.
\end{abstract}

\section{Keywords}

autism, music, musical empathy, embodiment, affect attribution 
One of the main symptoms of autism spectrum disorders is a disturbance of social skills, more particularly a disturbance of the ability to share the feelings and emotions with other persons. While this lack of empathy in autism subjects is evident in social contexts, it is less evident whether it also occurs in artistic contexts. This paper aims at testing to what extent subjects with autism can develop an empathic relationship with music through listening. The focus on music is of particular interest because music is known to be very rich in emotional content. Many (typically developing) people use music for consolation and they often engage in a kind of emotional relationship with the music $(1,2,3)$. A good example of this engagement is when people listen to sad music. In its proper context, listening to sad music may console a subject because it allows the subject to find relief in the imitation of the musical emotion, as if the music is just another social agent with whom it is possible to share emotions (4). The question is to what degree subjects with autism may find a similar relief in music, or in more general terms, to what degree they differ in musical empathy from a control group of typically developing subjects.

A number of studies have been addressing the role of music for people with ASD, thereby mainly focusing on the perception of musical structure. Several studies showed that ASD-subjects are superior to typically developing subjects when it comes to detailed processing of musical structures (5). Research of Heaton et al. (6,7,8), for example, showed that children with ASD outperform their matched controls on pitch discrimination, pitch categorization and pitch memory tasks. The results of Bonnel et al. (9) showed that subjects with ASD were superior to typically developing individuals in the pitch discrimination and categorization tasks.

Research on ASD and affect perception in music are much more rare. Musical affect has been addressed in a study by Heaton et al. (10). In this study, fourteen children with ASD and Asperger syndrome were tested for their ability to identify the affective connotations of melodies in the major and minor musical mode. They were required to match musical excerpts with schematic representations of happy and sad faces. The results showed that there were no differences between the clinical group and controls in their ability to ascribe the musical examples to the two affective categories. The authors concluded that in contrast to their performances within social and interpersonal relations, children with ASD showed no deficits in processing affect in musical stimuli. However, the fact that children with ASD could recognize emotional expression at this 
simple level might not be so surprising, given the fact that emotion recognition in people with ASD is not always impaired on all levels of complexity. Indeed, Capps et al. (11) and Baron-Cohen et al. (12) found that children with ASD were able to understand simple emotions. In the study of Capps et al. (11) it was also found that subjects with ASD could understand more complex emotions, although here they needed significantly more prompting and time than their matched controls.

In the present study, the relationship between people with ASD and music is studied from the viewpoint of embodied listening and embodied musical empathy. Empathy is traditionally described as the ability to share another person's feelings or emotions as if they were your own. Empathy with music would mean that humans have the ability to identify themselves with the emotional expressiveness embedded in the music. Leman ${ }^{(4)}$ defines several stages in this process of empathy with music, namely synchronization, corporeal attuning, corporeal imitation and emotional empathy. All these gradations are based on the idea that the listener can get access to the emotional system of the music through several gradations of corporeal involvement. This embodied view on musical empathy is in agreement with other findings in emotion research (13,14, 15) suggesting that the motor system may access the emotional system in different degrees of engagement. Synchronization is often displayed in tapping along the beat while listening $(16,17)$. Research has shown that subjects, even without being aware, tend to move body parts in synchrony with patterns in the physical stimulus $(18,19,20,21)$. Synchronizing the body with structural features (basic pulse, beat, or rhythm) in music can be interpreted as a non-inhibited motor re-synthesis of the perceived sonic patterns in the music. It allows the listener to feel and corporeally understand a basis structuring element in the music. In other words, it offers the listener the possibility to 'get into the music'. Corporeal attuning or harmonizing with music implies an active motor activity, involving control, short-term prediction and an engagement in goal-directed or intentional processes. In corporeal attuning with music the subject's body is aligned with the music's sonic forms. This alignment offers an opportunity for mirroring, that is, for experiencing the world from the viewpoint of the music's sonic forms (melody, harmony). Corporeal attuning thus provides a perfect context for empathy. Yet it should be noted that attuning is mainly involving the motor system, and not necessarily the emotional system. In emotional empathy, the subject enters a stage of being fully taken by the music, including both the 
motor and the emotional system. Music listening normally implies a straigthforward process from synchronization with the music to emotional understanding of the music, without experiencing a gap between motor and emotional system. Hence splitting up this process into discrete steps is artificial. However, in the present study we aim at investigating whether people with ASD can succesfully execute the different steps of this process, thus isolating each step in the empathic process, and whether they can establish a direct link between embodiment, cognition and empathy with music.

In the research presented here, the relationship between subjects with ASD and music is studied at three levels of empathic involvement, namely, synchronization, corporeal attuning and emotional empathy. Both synchronization and attuning are studied from the viewpoint of embodied listening, using kinematic devices for measurement. In contrast, the study on emotional empathy is a classic study involving verbal reporting. In the first and second experiment, subjects were asked to tap and draw along with the beat of the music. These two experiments tested their ability of synchronization. In a third experiment, subjects were asked to draw along with the melodic contour of the music, using an electronic pen and tablet equipment, testing their ability of corporeal attuning. In the fourth experiment subjects had to describe musical excerpts using affect-related adjectives. This task requires insight in the emotional content embedded in the music and thus investigates the ability of emotional empathy. Each subject in this study completed the four experiments within a timespan of two weeks.

\section{Experiments}

\section{Synchronization}

Two experiments aim at investigating the ability of people with ASD to synchronize their body movements to the musical beat. The first experiment is a study on tapping the beat, the second on drawing the beat. The studies differ in that tapping is monitored using a discrete method where each tap represents a discrete moment in time. Instead, drawing is monitored using a kinematic device that measures continuous movements. The drawing condition allows a study of implicit attuning effects, that is, of certain behavioral adaptations to the character of the music. 


\subsection{Synchronization by tapping the beat}

\section{Method}

The present experiment is an almost exact replica of an experiment carried out by McKinney \& Moelants (22) with typically developing subjects. A selection of musical excerpts was made out of the list of excerpts used in the experiment of McKinney \& Moelants(22), selecting those excerpts with an unambiguous beat perception by the majority of the typically developing participants. Their results were used as control group for the results of the clinical group of subjects with ASD.

Participants The clinical group was composed of 11 adult participants, all patients in a centre specialised in treatment and guidance of people officially diagnosed with ASD. The group was composed of 8 men and 3 women (mean age $=30$ ) and with normal to high IQ. Only subjects with a diagnosis of ASD, not combined with any other disorder (e.g. ADHD, ...) were included in the experiment. All subjects were tested individually and in their familiar surroundings.

Materials and stimuli 20 musical excerpts, with genre ranging from classical to pop, film music, metal (Appendix A) and duration of 30 seconds, were used in this experiment. All excerpts were stored in .wav-format and the intensity was normalized in order to avoid differences in loudness.

Procedure Participants were asked to tap along with the beat of the music by pressing the space bar on the keyboard of the computer. It was stressed that a regular pulse should be tapped, not a more complex rhythmical pattern. Participants were asked to tap simultaneously with the music, but when needed they could restart the excerpt as many times as they believed necessary. During the experiment participants very rarely needed or decided to take this second chance.

Analysis The tapped beats per minute (BPM) were calculated per musical excerpt and per participant, based on the calculation of the median of the tapintervals. These results were then compared to the BPM tapped by the majority of the participants in the experiment of McKinney \& Moelants (22) for the same musical excerpts. 


\section{Results}

Results show that a majority $(54,5 \%)$ of the clinical group succeeded very well in this synchronization task. However, a qualitative analysis revealed that a small group of subjects with ASD $(18,2 \%)$ had great difficulties in synchronizing their tapping with the beat of the music. Two groups could be distinguished who had more difficulties with this synchronization task. A first group (ASD 1, 3 and 11) (27,3\%) clearly tried to synchronize their tapping with the beat of the excerpts, but they tapped a little bit too fast or slow ( \pm 20 BPM). The second group (ASD 6 and 8) $(18,2 \%)$ tapped very irregularly. Apparantly, they were incapable of synchronizing their tapping with the beat of the music. During observation it was clear that ASD6 was constantly thinking, counting and searching for patterns that could be tapped, suggesting that synchronization with the beat is not an intuitive process for this subject. In short, in deviant synchronization two groups can be distinguished, namely a group that clearly tried to synchronize with the exact beat but did not succeed exactly and a group that did not synchronize at all. In the light of the present research it is interesting to see that a majority of the clinical group is capable of synchronizing with the beat of the music and thus are able to engage with music at this level.

\subsection{Synchronization and attuning by drawing}

\section{Method}

Participants 38 subjects served as participants in this experiments, 11 subjects diagnosed with ASD in the clinical group and 27 typically developing subjects in the control group. The clinical group was composed of the same subjects as the previous experiment. The control group was composed of 16 men and 11 women (mean age $=28,3$ ). All participants were tested individually and in their familiar surroundings.

Materials and stimuli Eight musical excerpts, with genre ranging from classiscal to jazz, pop and house (Appendix B) and duration of 30 to 35 seconds, served as stimuli in this experiment. They were selected from a larger set of excerpts based on the annotations of a group of six musicologists. This expert group determined the perceived tempo and the affective character of the stimuli. The resulting set consisted of excerpts ranging from slow to fast tempi, and with a 
fluent or stuttering character. All excerpts were stored in .wav-format and the intensity was normalized.

Procedure Participants were asked to draw along rhythmically with the music, using an electronic pen and tablet equipment. They were also asked to draw along with the flowing or stuttering character of the music, for example, fluid or round movements for a flowing rhythm (legato) and angular movements for a stuttering rhythm (staccato). The participants heard all excerpts two times. It was expected that the participants were able to draw in an immediate and spontaneous way along with the music, thus resulting in two drawings per excerpt.

Analysis In a first analysis, based on the actual drawings on the tablet, we studied whether or not participants were able to attune their drawing to the flowing or stuttering character of the music. In a second analysis, we studied the development of the drawings in time. In this representation, horizontal and vertical axes were summed up and plotted over time. These data were used for a periodicity analysis. The BPM's extracted from this analysis were then compared with reference BPM's for each stimulus.

\section{Results}

Results show that both clinical group (76\%) and control group (83\%) were able to synchronize their drawings with the flowing or stuttering character of the music. A minority of the clinical group had problems synchronizing their drawings to the character of the music (ASD 3, 6 and 11). ASD6 and ASD11 did not adapt their drawings at all to the changing character of the music (Figure 1a). ASD3 did change the drawing movements over different stimuli, but they were not in accordance with the flowing/stuttering character of the music (Figure 1b). The qualitative analysis of the actual drawings also revealed that a part of the clinical group (27\%) and of the control group (37\%) instinctively adapted certain features of their drawings to the bold/tender character of the music, although the experiment task did not prompt them to do this.

Results also show that a majority of the clinical group (64\%) and of the control group (85\%) were able to synchronize their drawings with the beat of the musical excerpts. These results are in complete accordance with the results of the previous tapping experiment. The same participants of the clinical group have difficulties with the synchronization task (ASD1, 3, 8 and 
11). ASD6 also had great difficulties with the first rhythmical tapping experiment, but he did succeed in synchronizing his drawings with the beat. His drawings however do reveal his search for patterns in the music and a perseverance for repetitive movement (Figure 2).

\section{Discussion}

Overall, in synchronized drawing to music people with ASD display little or no difference with a control group of typically developing subjects. In both groups, the majority of the subjects succeed in synchronizing with the beat of the music. Moreover, the study reveals that people with ASD are able to corporeally attune to the flowing/stuttering and bold/tender character of the music. We can thus conclude that people with ASD are able to engage with music at this level of musical empathy.

\section{Graphical attuning to melody}

\section{Method}

Participants Both clinical group and control group are the same as in the previous experiment. All participants were tested individually and in their familiar surroundings.

Materials and stimuli 11 monophonic musical excerpts, with genre ranging from classical to jazz, pop and film music (Appendix C) and with a duration of 30 to 35 seconds, were used as stimuli in this experiment. The monophonic melodies range from slow and more or less static melodic evolution to more complex melodic evolution. All excerpts were stored in .wav-format and the intensity was normalized.

Procedure Participants were asked to draw along with the melodic line of the unison musical excerpts, using an electronic pen and tablet equipment. All participants were instructed to move the pen along with the horizontal axis of the tablet. Moving the pen upwards is then interpreted as an ascending pitch and moving the pen downwards as a descending pitch. Given that the vast majority of the participants in both clinical and control group never had any musical education, all participants were given an introduction by the researcher and time to practice. During the experiment, participants heard all excerpts two times and were asked to draw along during each presentation of the excerpt, resulting in two drawings per excerpt. 
Analysis A series of plots aimed at visualizing the development of the drawing over time. These drawings were then compared with the melodic contour of the excerpts. This contour was extracted from the audio signal, using the MAMI Melody Transcriber (23). The subject's drawings were then compared to the extracted melodic contour. This was done manually and on a qualitative rather than quantitative basis.

\section{Results}

Analysis shows that both clinical group and control group can be divided into three subgroups, namely a group that attuned to the melody in a very precise way, a second group that attuned not very precisely and a third group that attuned in a very general way (Figure 3).

A comparison between the clinical group and the control group reveals that a higher percentage of people with ASD attunes in a very precise way to the melodic line of the musical excerpts. In the control group, most of the subjects attune in a very general way to the melodic line (Table 1).

\section{Discussion}

This corporeal attuning experiment shows that the majority of the ASD-subjects are very capable to attune their movements with the melodic contour of the musical excerpts. Comparison with a control group even shows that the subjects with ASD outperform the subjects in the control group. These results are in accordance with results of previous studies ${ }^{(6,9)}$ and can be explained by the weak urge for central coherence that is characteristic for people with ASD. In the weak central coherence theory ${ }^{(24)}$, it is assumed that people with ASD have a cognitive style which biases processing in favour of local features and predicts enhanced performance on tasks where good featural processing conveys an advantage, such as in the present attuning task. This experiment shows that people with ASD tend to display more attention to the different notes of the melody, rather than to the melodic contour when listening to music.

\section{Attribution of affective qualities}

The findings of the previous experiment raise the question whether a particular focus on structural features (rhythm, pitches, a.o.), as seems to be typical for people with ASD, would 
imply a restriction to a low-level comprehension of the musical expression or the musical rich emotional content.

\section{Method}

Participants This experiment is an almost exact replica of an experiment carried out by Lesaffre (25) with typically developing participants. Results from the latter experiment are used as control for the results from the clinical group tested in this experiment.

The clinical group is identical to the clinical group in the previous experiments. The subjects were again tested individually and in their familiar surroundings.

Materials and stimuli 20 musical excerpts were selected from the 160 musical excerpts used in the experiment of Lesaffre (25) (Appendix D). Preference was given to those excerpts with unanimity of affective appreciation among the typically developing participants. All excerpts had a duration of 30 seconds, were converted to .wav-format and the intensity was normalized.

Procedure Using paper questionnaires, participants were asked to describe the 20 musical excerpts using affect-related adjectives. Per excerpt seven unipolar affect-related adjectives (anxious, passionate, sad, aggressive, cheerful, careless, tender) had to be evaluated on a fivepoint scale, and four bipolar adjectives (hard-soft, slow-fast, dynamic-static, flowing-stuttering) had to be evaluated on a scale from -4 to 4 . To limit the impact of ability of language processing, the affect-related adjectives were visualized using photographs of facial expressions (26). The recognition of the affective facial expressions by the participants was tested before execution of this experiment. The experiment had no time limitations.

\section{Results}

Results show that the clinical group in this experiment appreciated the musical excerpts in the same way as the typically developing subjects in the experiment of Lesaffre ${ }^{(25)}$. Analysis of the calculated correlations for the data set of each participant also show that there is great consistency in the answers of the participants. We can thus conclude that people with ASD have the ability to perceive affect in music and can engage in an empathic relationship with music. 
However, since the experiment did not have any time limitations, the duration of the experiment is also an important factor to take into account. In the experiment of Lesaffre (25) participants had to appreciate 160 musical excerpts during four sessions with 40 musical excerpts per session. Depending on the amount of times the participants listened to each musical excerpt, the duration of the experiment for one session of 40 stimuli varied between 60 and 120 minutes. The mean time taken to evaluate each excerpt is about two minutes. In the present experiment with a clinical group of people with ASD, only 20 musical excerpts were offered. For the clinical group, the duration of the experiment varied between 140 and 280 minutes (executed in two to four different sessions). In the mean, each excerpt took about 10,5 minutes to evaluate.

\section{Discussion}

This experiment shows that people with ASD are able to assign affect-related adjectives to music, but they need a lot more time and prompting to complete this task in comparison with typically developing subjects. The present findings are in accordance with the results of Heaton et al. (6) in which it was shown that children with ASD showed no deficits in processing affect in musical stimuli. However, when we take into account the duration of the experiment, a very significant difference appears. Typically developing subjects are able to evaluate the affective character of music very fast, whereas subjects with ASD seem to reason, evaluate and compare. It is af if they rely less on corporeal imitation of emotions but more on observation and associated disembodied processing. In typically developing individuals, the motor activity, synchronization and imitation, offers a straigthforward and spontaneous access to get into the music. In people with ASD, it seems as if this link between corporeal articulation and empathy is less clearly established. Instead they rely upon cognitive reasoning and this explains why people with ASD need a lot more time for this task.

When specifically asked, people with ASD are capable of recognizing and attributing affects to music, they are able to theorize about affective features in the music, but they clearly rely on disembodied, cognitive processes to complete this task. Since participants with ASD are capable of mirroring musical affects into corporeal articulations but lack a straightforward process to social cognition, a distinction should be made between a corporeal/embodied engagement kinesic theory of mind - with the music on the one hand and emotional understanding - semantic 
theory of mind - of the music on the other hand (4). The findings of the present studies show that people with ASD are capable of kinesic theory of mind, since they are able to synchronize and attune their body with structural and affective features of the music, but this does not enable a direct link with emotional understanding of these affective features in the music.

\section{Conclusion}

Four experiments, aimed at investigating the degree in which people with ASD are able to engage with music, were carried out. Based on the idea that coherent perception of music and emotional involvement with music is possible through corporeal mediation, the concept of musical empathy was divided into several gradations, ranging from synchronization and attuning to emotional involvement.

The results show that in synchronized tapping and drawing to music, subjects with ASD display little or no difference with a control group of typically developing subjects. The study also revealed that people with ASD are able to corporeally attune their drawing, both in a controlled and spontaneous way, to affective features in the music. The majority of people with ASD attune their movements with the melodic contour of the musical excerpts and they outperform their non-autistic controls by moving in a more precise way in accord with the melody. Finally, in a study on verbal description of musical affects we found that people with ASD are capable of attributing affective qualities to music, but they needed significantly more time than typically developing controls.

The present research shows that people with ASD have a corporeal understanding of the affective features of music, since they are able to mirror structural and even affective features of the music into corporeal articulations. However, when musical empathy involves emotional processing, we found clear differences with typically developing controls. People with ASD seem to rely on disembodied cognitive processes to attribute affects to music, indicating that their corporeal understanding does not give them a straightforward access to the emotional content of the music. Further studies with larger sample sizes should be conducted to elaborate further on this concept.

The present study shows that music can be used as a tool to diagnose certain aspects of empathic involvement. Research on musical empathy in people with ASD offers the outline of a new, 
comprehensive approach to a better understanding, and possibly diagnosis and treatment of people with this pervasive social disorder and can also offer a more profound insight in the processes that involve processing of affective musical features and hence contribute to the domain of music therapy. This embodied approach to musical empathy could lead to a new methodology in music therapy. By training the embodied understanding of affective features in music, and clarifying and training the link between this embodiment and the semantic understanding of the emotions in the music, music therapy may establish and enhance the automated process of synchronization to emotional empathy with music in subjects with ASD.

\section{Acknowledgements}

The authors wish to thank the Fonds voor Wetenschappelijk Onderzoek Vlaanderen (FWO) for funding this research. We would like to thank Frank Desmet, Micheline Lesaffre, Dirk Moelants and Frederik Styns for their help in the set up and analysis of the experiments. We also want to thank Christel Embrechts of the music therapy department of vzw Caritas and the psychologists and participants of vzw Het Anker.

\section{References}

${ }^{1}$ DeNora T. (2001). Aesthetic agency and musical practice: New directions in the sociology of music and emotion. In P.N. Juslin \& J.A. Sloboda (Eds.) Music and Emotion: Theory and Research (pp. 161-180). Oxford: Oxford University Press.

${ }^{2}$ Thompson W.F. (2009). Music, thought, and feeling: Understanding the psychology of music (pp. 141-144, 253). Oxford: Oxford University Press.

${ }^{3}$ Juslin P.N. (2009). Emotional responses to music. In S. Hallam, I. Cross \& M. Thaut (Eds.) The Oxford handbook of music psychology (pp. 131-140). Oxford: Oxford University Press.

${ }^{4}$ Leman M. (2007). Embodied music cognition and mediation technology. Cambridge, MA: The MIT Press.

${ }^{5}$ Applebaum E., Egel A., Koegel R., and Imhoff B. (1979). Measuring musical abilities of autistic children. J Autism Dev Disord, 9(4), 279-285. 
${ }^{6}$ Heaton P., Hermelin B., and Pring L. (1998). Autism and pitch processing: A precursor for savant musical ability? Music Percept, 15(3), 291-305.

7 Heaton P., Pring L., and Hermelin B. (2001). Musical processing in high functioning children with autism. Biol found Music, 930, 443-444.

${ }^{8}$ Heaton P. (2005). Interval and contour processing in autism. J Autism Dev Disord, 35(6), 787793.

${ }^{9}$ Bonnel A., Mottron L., Peretz I., Trudel M., Gallun E., and Bonnel A.-M. (2003). Enhanced pitch sensitivity in individuals with autism: A signal detection analysis. J Cogn Neurosci, 15(2), 226235.

${ }^{10}$ Heaton P., Hermelin B., and Pring L. (1999). Can children with autistic spectrum disorders perceive affect in music? An experimental investigation. Psychol Med, 29(6), 1405-1410.

${ }^{11}$ Capps L., Yirimiya N., and Sigman M. (1992). Understanding of simple and complex emotions in non-retarded children with autism. J Child Psychol Psychiatry, 33, 1169-1182.

12 Baron-Cohen S., Tager-Flusberg H., and Cohen D. (1993). Understanding others' minds: Perspectives from autism. Oxford: Oxford University Press.

13 Niedenthal P.M., Augustinova M., and Rychlowska M. (2010). Body and Mind: Zajonc's (re)introduction of the motor system to emotion and cognition. Emotion Rev, 2(4), 340-346.

14 Carr L., Iacoboni M., Mazziotta J., and Lenzi G. (2003). Neural mechanisms of empathy in humans: A relay from neural systems for imitation to limbic areas. Proceedings of the National Academy of Sciences of the United States of America, 100(9), 5497-5502.

${ }^{15}$ Leslie K., Johnson-Frey S., and Grafton S. (2004). Functional imaging of face and hand imitation: towards a motor theory of empathy. Neurol., 21(2), 601-607.

${ }^{16}$ Desain P., and Windsor W. (2000). Rhythm perception and production. Lisse: Swets \& Zeitlinger.

17 Thaut M. (2005). Rhythm, music and the brain: Scientific foundations and clinical applications. New York: Routledge.

${ }^{18}$ Fraisse P. (1963). The psychology of time. Westport, CT: Greenwood Press.

${ }^{19}$ Michon J. (1967). Timing in temporal tracking. Assen, The Netherlands: Van Gorcum.

20 Schachner A., Brady T.F., Pepperberg I.M., Hauser M.D. (2009). Spontaneous motor entrainment to music in multiple vocal mimicking species. Curr Biol, 19, 831-836.

${ }^{21}$ Large E.W. (2000). On synchronizing movements to music. Hum Movement Sci, 19, 527-566. 
22 McKinney F., and Moelants D. (2006). Ambiguity in tempo perception: What draws listeners to different metrical levels? Music Percept, 24(2), 155-166.

${ }^{23}$ De Mulder T., Martens J., Lesaffre M., Leman M., De Baets B., and De Meyer H. (2003). An auditory model based transcriber of vocal queries. In Proceedings of the fourth international conference on music information retrieval (ISMIR 2003), 245-246.

${ }^{24}$ Frith U. (1989). Autism: Explaining the enigma. Blackwell.

25 Lesaffre M. (2005). Music information retrieval: Conceptual framework, annotation and user behaviour. Unpublished doctoral dissertation, Ghent University.

${ }^{26}$ Ekman P. (1992). An argument for basic emotions. Cognition Emotion, 6, 169-200.

\section{Corresponding address}

Leen De Bruyn, Ghent University, Department of Musicology (IPEM), Blandijnberg 2, 9000 Gent, Belgium, Email: Leen.DeBruyn@UGent.be 


\section{Tables}

\begin{tabular}{|c|c|c|}
\hline Subgroups & ASD & CG \\
\hline general & $18 \%$ & $44 \%$ \\
\hline precise & $27 \%$ & $19 \%$ \\
\hline very precise & $55 \%$ & $37 \%$ \\
\hline
\end{tabular}

Table 1: $\quad$ Percentages of ASD (clinical group) and CG (control group) that attune to melody in a general, precise and very precise way to the melodic line.

\section{Figures}
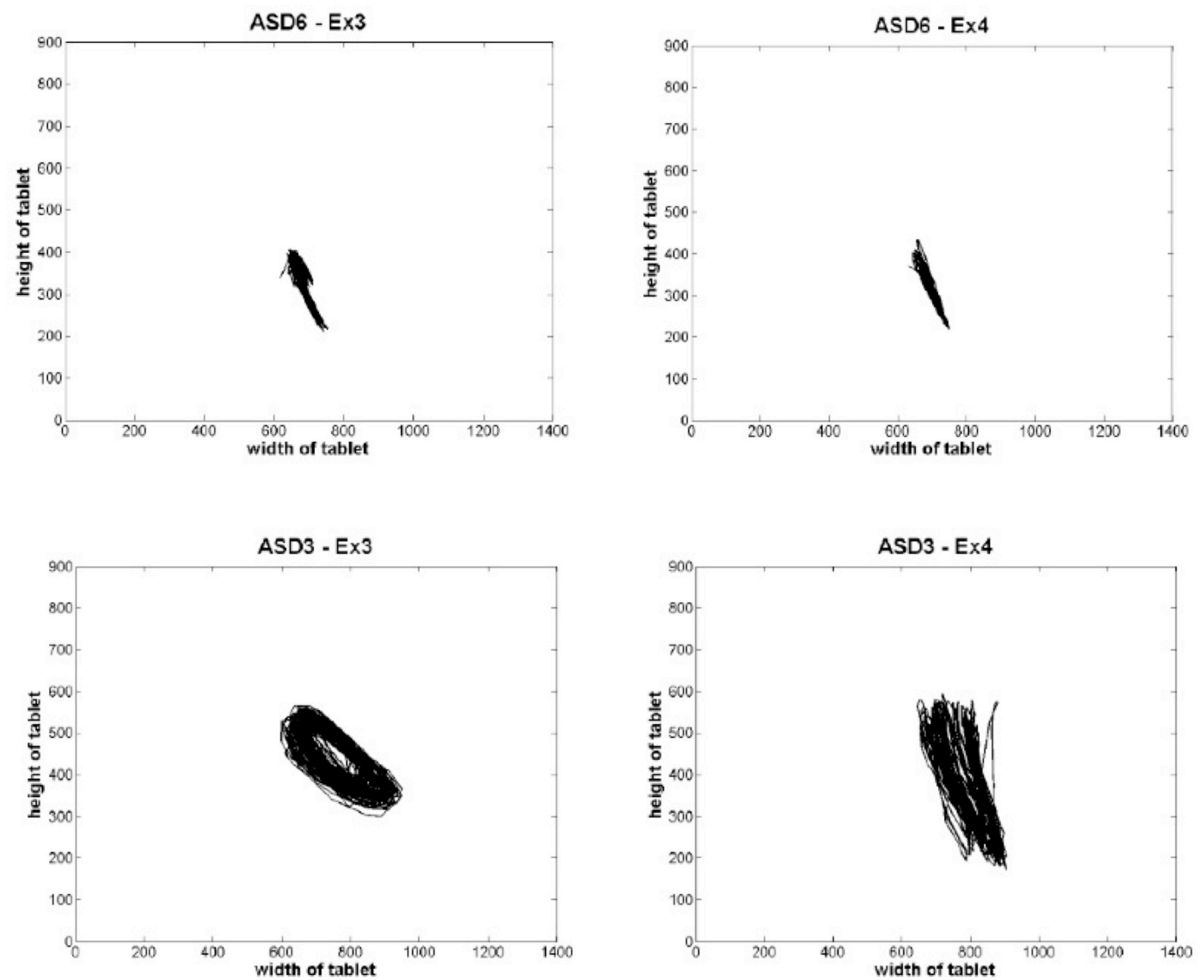

Figure 1: $\quad$ (a) Rhythmical drawings of ASD6 for the bold and stuttering excerpt 3 (Nitro doll - Rocket City Riot) and the tender and flowing excerpt 4 (Pavan 'Lord Salisbury' - Orlando Gibbons). (b) Rhythmical drawings of ASD3 for excerpts 3 and 4 . 


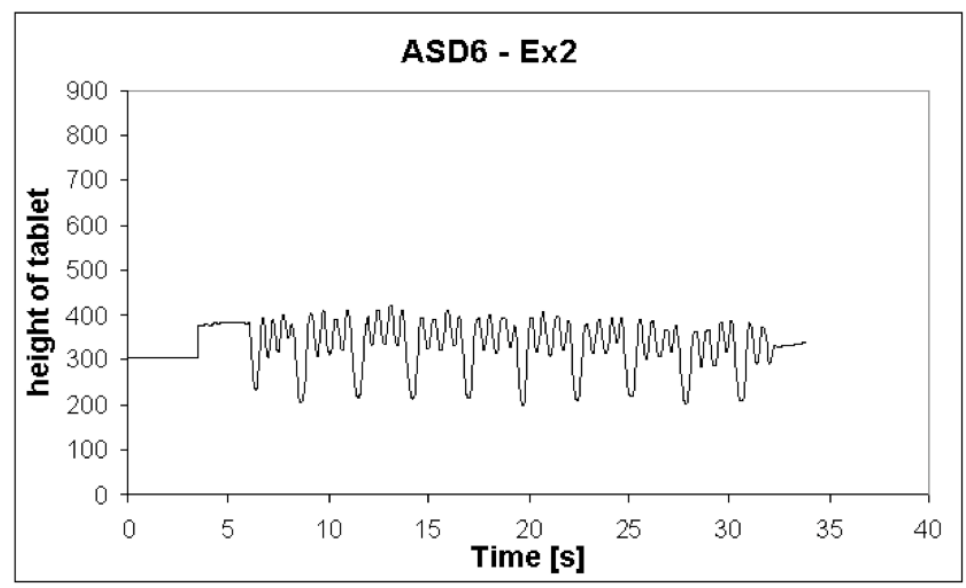

Figure 2: $\quad$ Rhythmical drawing of ASD6 for excerpt 2, showing a perseverance for a repetitive pattern in the music. 

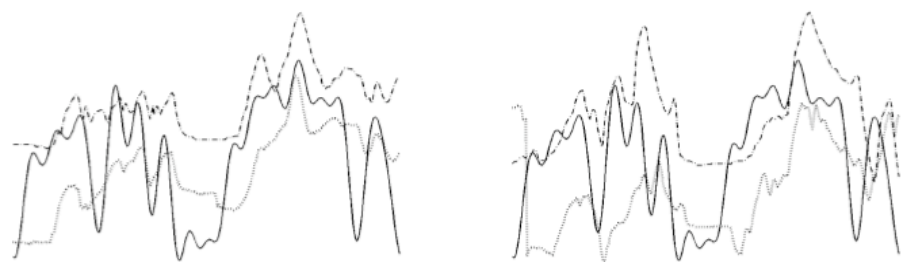

\section{EXACT}
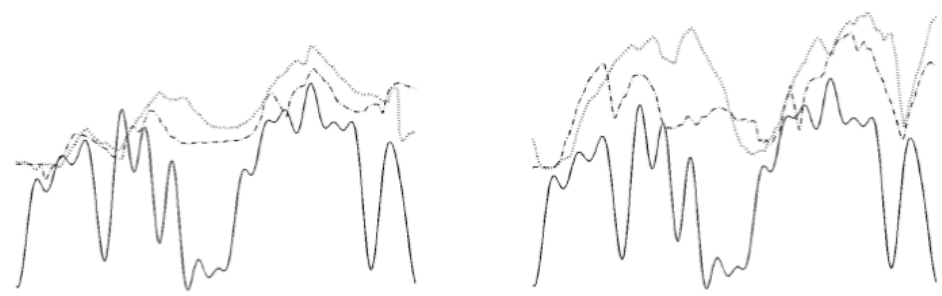

\section{GENERAL}

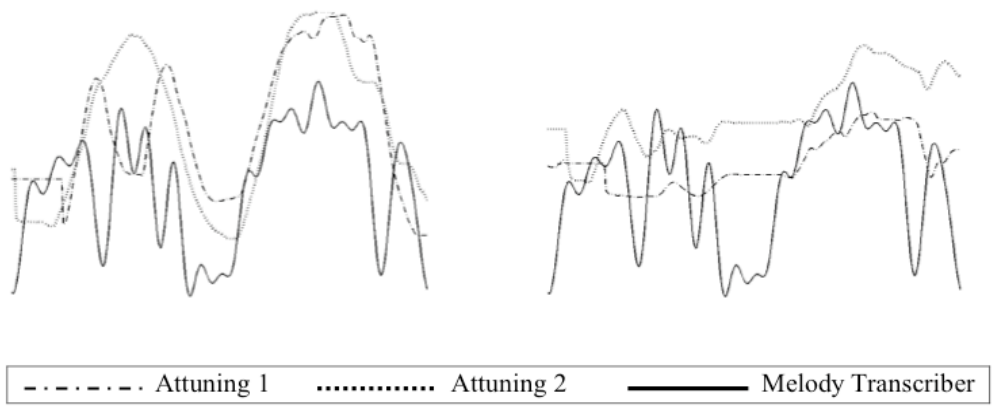

Figure 3: Visual representations of the graphical attuning to the melodic contour for excerpt 1. In the columns you see a comparison of subjects in the clinical group (ASD) and the control group (CG). In the rows you see a comparison of subjects that attuned to the melody in a very exact, exact and general way. 


\section{Appendix}

\begin{tabular}{|c|c|c|c|}
\hline Excerpt Number & Title & Performer/Composer & BPM \\
\hline Excerpt 1 & La valse d'Amélie & Yann Tiersen & 49 \\
\hline Excerpt 2 & Aoi Hitomi & Maaya Sakamoto & 52 \\
\hline Excerpt 3 & $\mathrm{Zij}$ & Marco Borsato & 56 \\
\hline Excerpt 4 & Artichoke & Cibo Matto & 60 \\
\hline Excerpt 5 & Devil got my woman & Skip James & 80 \\
\hline Excerpt 6 & Crockett's Theme & Jan Hammer & 96 \\
\hline Excerpt 7 & Inch'Allah & Mc Solaar & 103 \\
\hline Excerpt 8 & Been caught stealing & Jane's addiction & 104 \\
\hline Excerpt 9 & Respect & Otis Redding & 114 \\
\hline Excerpt 10 & Highway to hell & $\mathrm{AC} / \mathrm{DC}$ & 115 \\
\hline Excerpt 11 & Azzuro & Adriano Celentano & 118 \\
\hline Excerpt 12 & Come di & Paolo Conte & 130 \\
\hline Excerpt 13 & Three o'three & Public energy & 140 \\
\hline Excerpt 14 & The Message & Zolex & 140 \\
\hline Excerpt 15 & Come take my hand & 2 brothers on the 4 th floor & 168 \\
\hline Excerpt 16 & I'll take you all to fucking hell & Scarface & 170 \\
\hline Excerpt 17 & Torremolinos & Sttellla & 176 \\
\hline Excerpt 18 & Sabeldans & Aram Khachaturian & 178 \\
\hline Excerpt 19 & Silver Rocket & Sonic Youth & 185 \\
\hline Excerpt 20 & El gato lopez & Ska-P & 220 \\
\hline
\end{tabular}

Appendix A: List of stimuli used in the synchronization by tapping experiment. 


\begin{tabular}{|l|l|l|l|l|}
\hline Excerpt & \multicolumn{1}{|c|}{ Title } & Performer/Composer & Character & \multicolumn{1}{|c|}{ BPM } \\
\hline Number & $\begin{array}{l}\text { Triosonate op. 2, no. } \\
\text { 2 in g-minor } \\
\text { (allegro) }\end{array}$ & Georg Friedrich Händel & Stuttering & 94 \\
\hline Excerpt 2 & Disconnected & Emma's Mini & Flowing & 88 \\
\hline Excerpt 3 & Nitro doll & Rocket City Riot & Stuttering & 193 \\
\hline Excerpt 4 & $\begin{array}{l}\text { Pavan "Lord } \\
\text { Salisbury" }\end{array}$ & Orlando Gibbons & Flowing & 77 \\
\hline Excerpt 5 & Trance Odyssey & DJ Markitos & Stuttering & 150 \\
\hline Excerpt 6 & Hey now babus & Tom Paul & Flowing & 83 \\
\hline Excerpt 7 & Malo Selo & Kitka & Flowing & 54 \\
\hline Excerpt 8 & $\begin{array}{l}\text { Einfach, } \\
\text { Davidsbündlertänze } \\
\text { op. 6, no. 11 }\end{array}$ & Robert Schumann & Flowing & 91 \\
\hline
\end{tabular}

Appendix B: $\quad$ List of stimuli used in the synchronization by drawing experiment.

\begin{tabular}{|l|l|l|}
\hline Excerpt Number & \multicolumn{1}{|c|}{ Title } & \multicolumn{1}{c|}{ Performer/Composer } \\
\hline Excerpt 1 & 0 quam mirabilis est & Hildegard von Bingen \\
\hline Excerpt 2 & Sequenza I for flute solo & Luciano Berio \\
\hline Excerpt 3 & Alleluia & Chant de l'église Milanese \\
\hline Excerpt 4 & Solo Luc & Olla Vogala \\
\hline Excerpt 5 & La Dispute & Yann Tiersen \\
\hline Excerpt 6 & Saxophone solo & $/$ \\
\hline Excerpt 7 & Flute solo & $/$ \\
\hline Excerpt 8 & Wampum prayer & Tori Amos \\
\hline Excerpt 9 & Violin and recorder & $/$ \\
\hline Excerpt 10 & Double-bass solo & $/$ \\
\hline Excerpt 11 & Le Moulin & Yann Tiersen \\
\hline
\end{tabular}

Appendix C: $\quad$ List of stimuli used in the melodic attuning experiment. 


\begin{tabular}{|c|c|c|}
\hline Excerpt Number & Title & Performer/Composer \\
\hline Excerpt 1 & Ah, vita bella & Lucilla Geleazzi \\
\hline Excerpt 2 & Le Sacre du Printemps & Igor Stravinski \\
\hline Excerpt 3 & Concerto for violin and orchestra, Canzonetta & Pjotr Tchaikovski \\
\hline Excerpt 4 & St. Anger & Metallica \\
\hline Excerpt 5 & The robots & Kraftwerk \\
\hline Excerpt 6 & Many meetings & Howard Shore \\
\hline Excerpt 7 & Pianoconcerto Nr. 1 in c, op. 18, 3rd movement & Sergei Rachmaninov \\
\hline Excerpt 8 & Achterbank & De Nieuwe Snaar \\
\hline Excerpt 9 & Tears in Heaven & Eric Clapton \\
\hline Excerpt 10 & Tame & The Pixies \\
\hline Excerpt 11 & Traffic & DJ Tiesto \\
\hline Excerpt 12 & One Step & Tam Echo Tam \\
\hline Excerpt 13 & A tisket a tasket & Ella Fitzgerald \\
\hline Excerpt 14 & Messa de Requiem, Dies Irae & Guiseppe Verdi \\
\hline Excerpt 15 & Die Walküre, Vorspiel & Richard Wagner \\
\hline Excerpt 16 & Gymnopédie No. 1 & Eric Satie \\
\hline Excerpt 17 & My World & Metallica \\
\hline Excerpt 18 & From the cradle to enslave & Cradle of Filth \\
\hline Excerpt 19 & Libertango & Astor Piazolla \\
\hline Excerpt 20 & Tic Tic Tac & Carrapicho \\
\hline
\end{tabular}

Appendix D: List of stimuli used in the affect attribution experiment. 